\title{
How to Digitally Enhance Bioeconomy Collaboration: Multidisciplinary Research Team Ideation for Technology Innovation
}

\author{
Essi Ryymin, Laura Lamberg \& Annukka Pakarinen
}

\author{
" The future is built on the flow of new ideas." \\ Paul Meyer
}

\begin{abstract}
In this paper we examine the potential of digital platforms for managing multidisciplinary collaboration and particularly the ideation processes of multidisciplinary research and development in the case of technology-supported vertical farming. The article draws on research data from semi-structured interviews and a collaborative workshop that was conducted with researchers representing biological, digital, and technological domains. The results of this research indicate that digital platforms may offer impactful, processaccelerating support during the kick-off phase of multidisciplinary technological innovations. A digital platform can support ideation and the prioritisation of ideas and can be especially fruitful when paired with face to face discussion and non-digital interaction.
\end{abstract}

\section{Introduction}

As the Earth's temperatures rise, biodiversity is plummeting, soil nutrients are being lost, and the world population keeps growing. The need for fundamental changes in the agri-food sector now seems undeniable. Technological advancement has often been touted as a solution on the road to sustainability, and in recent decades the conversation has been enriched by frameworks such as the socio-technical transitions approach (Geels, 2011, 2019). According to this approach, sustainability transitions rely on taking a systemic outlook to change: technological advancement is key, but so also is restructuring social meanings, consumer behavior, policies, business models, and so on (Geels, 2019). This requires the involvement of multiple actors in different fields of life - scientists in various disciplines, policymakers, educators, and industry alike.

The introduction and development of new technology creates opportunities and challenges for research much beyond the obvious fields of engineering. In the case of the agri-food sector, innovations such as vertical farming have fostered research and development that brings together researchers across disciplinary boundaries. When knowledge about socio-ecological problems is incomplete, multidisciplinary (or transdisciplinary) research can be used to address problems and seek solutions that hold important implications for those affected by them (Norris et al., 2016, referring to Pohl \& Hirsch Hadorn, 2007). "Multidisciplinarity" has thus become necessary to understand the complex nature of ecological sustainability problems, to experience various contributions from different disciplinary backgrounds, and to offer a more complete corresponding set of tools (for example, technical, behavioral, individual, and organisational) for addressing and preventing sustainability challenges in real-life.

However, practicing multidisciplinarity can be very challenging. Researchers from different backgrounds must learn to understand and appreciate each other's perspectives (Schoot Uiterkamp \& Vlek, 2007). Previous research has identified a long list of challenges associated with multidisciplinary research (Ramadier, 2004; Schoot Uiterkamp \& Vlek, 2007; Pohl \& Hirsch Hadorn, 2008). An especially challenging problem arises in framing the research and research problems (Lang et al., 2012). 


\section{How to Digitally Enhance Bioeconomy Collaboration: Multidisciplinary Research Team Ideation for Technology Innovation Essi Ryymin, Laura Lamberg \& Annukka Pakarinen}

For this study, our interest was to investigate multidisciplinary collaboration of a research team tackling sustainability issues in the agri-food sector. With this aim in mind, the objective was to investigate a digitally-supported ideation workshop as a method for the definition of research ideas in a multidisciplinary team. The context of the study was a development project of smart and sustainable bioeconomy delivered in a higher education institution. The project's strategic goals called for responding to the need for sustainable food production, while addressing the megatrends of digitalisation and climate change. The development project aimed at creating multidisciplinary sustainable innovations through data-driven knowledge creation in the bioeconomy. The higher education institution researchers and network of bioeconomy companies worked in close transdisciplinary co-operation during the project.

Our specific focus of interest was on a multidisciplinary team of researchers, which was researching and developing "smart vertical farming". Vertical farming is a novel practice that is expected to supply food to cities sustainably or with value-added biomass for the industry (Al-Chalabi, 2015). The higher education institution recently started a sustainability-oriented research project on vertical farming, which included implementing data analysis in optimising biomass production in controlled conditions at a container farm. Research in a controlled cultivation environment enabled various possibilities for the participants. This ranged from finding solutions to fight against hunger in a changing climate, to optimising plant growing conditions in order to help aid in transition from the current fossil economy to a biobased economy, by producing specific biobased compounds for further products.

The significant goal of the smart vertical farming project is to create digitalized measurements, including for IoT (Internet of Things)-based data collection, analysis, and interpretation in analysing, monitoring, and optimising the vertical farming production chains. The project brings together multiple research interests and competences in the life sciences, technology, digital services, and the field of education to investigate the research area of sustainable and smart bioeconomy.

The first phase of the smart vertical farming project was the building of a collaborative research team and setting of agreed-upon research ideas and interests. Essential in this phase is that a real-world challenge is translated into a prominent research idea, a boundary object, that is both researchable and allows for the re-integration of insights from different scientific bodies of knowledge (Lang et al., 2012).

\section{Multidisciplinary Teamwork and Collaborative Ideation in a Digital Age}

Several authors have recognised challenges in knowledge sharing and joint endeavours when working on a complex object of research activity in multidisciplinary collaboration (Ramadier, 2004; Schoot Uiterkamp \& Vlek, 2007; Pohl \& Hirsch Hadorn, 2008; Lang et al., 2012).

Edwards (2010, 2012) developed a compelling theoretical concept called "relational expertise" for analysing and conceptualising collaboration between experts. By relational expertise Edwards means a form of expertise that augments one's specialist expertise and makes responsive collaboration possible. Relational expertise involves the ability to take into account the standpoints of other collaborators, recognise what matters to them when working on an project, make visible to them what matters for you, jointly expand the interpretation of the task, and calibrate responses so that experts can work on it together (Edwards, 2017). Relational expertise enables greater relational agency, wherein people are able to work together on complex activities (Edwards 2010, 2012, 2017). Relational agency involves expanding upon singular interpretations of a phenomenon by bringing to bear the different expertise or conceptual resources offered by work collaborators. This expansion means that more relevant aspects of phenomenon can be recognised and worked on (Edwards, 2017).

Fong (2003) introduced a model of knowledge creation within multidisciplinary project teams that places primary emphasis on processes, rather than outcomes. In the model, five processes of knowledge creation are identified and intertwined: 1) boundary-crossing, 2) knowledge-sharing, 3) knowledge generation, 4) knowledge integration, and 5) collective project learning. Below we expand on each of these processes in the model.

First, crossing boundaries successfully requires personal conversations among team members. Visualised objects of activity, such as shared drawings, can help with team interaction. Second, knowledgesharing creates benefits when project team members 


\section{How to Digitally Enhance Bioeconomy Collaboration: Multidisciplinary Research Team Ideation for Technology Innovation Essi Ryymin, Laura Lamberg \& Annukka Pakarinen}

come from different knowledge domains. In such cases, they are more likely to discuss their unique knowledge and distinct information, than among those who possess knowledge or information in common. Third, in the process of knowledge-generation, creative teams aim to generate new or emerging knowledge vital for innovation. Fourth, knowledge integration combines differing perspectives and integrates knowledge from various disciplines in the decision-making process. Team members bring different sets of assumptions about optimal ways to proceed in their teamwork, thereby prioritising diverse values and perspectives, which ultimately aim to best meet the current challenges. In the fifth process of collective project learning, professionals learn from the projects they engage. Here, support for the problem-solving and reflection processes of the team and team members is important. Through these interwoven processes, new or emerging knowledge can be created within a project team, likewise existing knowledge can be combined to form new insights (Fong, 2003).

Vick and colleagues (2015) studied a variety of university research teams engaged in collaborative innovation, looking at how their information culture influences knowledge creation. They found that multidisciplinary teams emphasise interpersonal relations and encourage the presentation of information in a common language to promote better understanding among members from different disciplines (Vick et al., 2015).

Paulus, Baruah, and Kenworthy (2018) studied collaborative ideation in organisations. They found that although theoretical perspectives regarding collaborative ideation often suggest positive outcomes, the actual interaction processes that happen in groups may not be well- structured for the impactful sharing of ideas and their further development. For instance, in face-to-face group settings only one person can effectively share ideas at one time. This limits the similar opportunity for others in that same time frame. A highly recommended alternative is to use a digital method for exchanging ideas. Many platforms are now available with user processes that allow participants to generate ideas in real time, and to examine and respond to ideas shared by others. These systems also allow for voting and collectively deciding on best ideas. Digitally supported methods tend to be more efficient in generating a higher volume of ideas with the help of an online community, compared with using one-way only speaker method (Dennis et al., 2019).
Various modifications to traditional brainstorming have been made based on digitally mediated communication, for instance, brainwriting and electronic brainstorming. These methods have advantages over face-to-face brainstorming, such as opportunities to contribute ideas simultaneously. Further, ideas can be easily recorded this way, with little to no risk of dominance by one or a few participants (Yagolkovskiy, 2015). Kerr and Murthy (2009) found that participants using computer-mediated communication platforms perform significantly better on divergent brainstorming tasks than those interacting face-to-face. Contrary to traditional brainstorming, the decision quality was also higher when made digitally in large computer-mediated groups, and the groups generated more alternatives.

According to Korde and Paulus (2017), the most effective brainstorming process is one that involves variation in individual and group ideation; a kind of hybrid brainstorming. Variation leads to the best performance in terms of number of ideas generated and enhances the cognitive perspective of group creativity. Also, Jensen and co-authors (2018) studied both face-to-face (physical) and digital (online) collaborative ideation, and they argue that collaborative ideation can successfully be supported digitally. The next step in improving the technological setup for collaborative ideation does not, however, require an either-or scenario. Instead, it should bring the best of the two worlds, physical and digital, together.

Helping to work towards this goal, we set as an objective for this study to investigate two lines of inquiry: firstly, the expectations of researchers, and secondly, the results of digitally collaborative ideation. We thus posed the following research questions: What were the expectations from the multidisciplinary researchers of smart and sustainable bioeconomy, regarding their reciprocal collaboration? And what were their expectations for the smart vertical farming project? Additionally, the study assesses how a digital platform was implemented with an aim to enhance the collaborative ideation process of research ideas in the smart vertical farming project. Hence, we asked: what were the results of the digitally enhanced collaborative ideation, and what value did the digital platform provide to the ideation process? In answering these questions, we reflected on the impact of the digital platform, by assessing feedback from the researchers as well as comparing the results of ideation to the researchers' initial expectations. 


\section{How to Digitally Enhance Bioeconomy Collaboration: Multidisciplinary Research Team Ideation for Technology Innovation Essi Ryymin, Laura Lamberg \& Annukka Pakarinen}

\section{Data Collection and Methodological Approach}

The data in this study comes from eleven (11), one-onone semi-structured interviews with researchers involved in a smart and sustainable bioeconomy development project, and a collaborative ideation workshop with six (6) researchers focusing on smart vertical farming. Five of the six participants of the vertical farming workshop also belonged to the interviewed eleven researchers, while one of the six did not. The interviewees broadly represented biological science, digital, and technological domains, whereas the backgrounds of the workshop participants ranged across different sub-disciplines of the life sciences (for example, bioprocess and automation engineering, horticulture, environmental engineering, chemistry).

The key themes covered in the interview process were the interviewees' expectations related to multidisciplinary collaboration between researchers from different domains, along with their expectations, especially for the newly launched smart bioeconomy project. In the collaborative ideation workshop, participants explored and discussed their research ideas concerning smart vertical farming. The interviews and the workshop were recorded, transcribed, and analysed. Additionally, the activities of workshop members in the digital platform were archived in the platform's database and analysed. The study used qualitative analysis to gain insights into the expectations of project partners towards multidisciplinary co-operation. The collaborative character of the workshop offered another advantage for analysing group discussion, knowledge sharing, and using a digital platform in research idea framing. The qualitative data analysis included selecting relevant texts for further analysis related to the theoretical framework and previous research. Specific attention was paid to so-called "repeating ideas" (Auerbach \& Silverstein, 2003). In the last phase, coherent categories were grouped into more abstract themes and concepts.

\section{Results}

\section{Researcher Expectations}

Our analysis of interview data revealed several expectations for multidisciplinary co-operation and smart vertical farming. The themes identified in the interviews are summarised in Table 1.

The interviewees expected multidisciplinary collaboration to generate new solutions for wicked problems involving sustainability, especially in carbon binding towards preventing climate change. In the context of smart vertical farming, the interviewees predicted new solutions for climate-friendly food

Table 1. Expectations of interviewees for multidisciplinary collaboration and smart vertical farming

\begin{tabular}{|c|c|l|}
\hline Expectations & \multicolumn{1}{|c|}{$\begin{array}{c}\text { Multidisciplinary } \\
\text { Collaboration }\end{array}$} & \multicolumn{1}{c|}{ Smart Vertical Farming } \\
\hline $\begin{array}{c}\text { Solutions for } \\
\text { Sustainability }\end{array}$ & $\begin{array}{l}\text { New solutions to wicked } \\
\text { problems of sustainability, } \\
\text { especially carbon binding in } \\
\text { prevention of climate change } \\
\text { by combining different } \\
\text { scientific approaches. }\end{array}$ & $\begin{array}{l}\text { New solutions for climate- } \\
\text { friendly food production to } \\
\text { fight against hunger and } \\
\text { energy-savvy, controlled } \\
\text { cultivation of plants. }\end{array}$ \\
\hline New Competences & $\begin{array}{l}\text { New competences in data- } \\
\text { driven, smart bioeconomy } \\
\text { by combining different } \\
\text { scientific approaches. }\end{array}$ & $\begin{array}{l}\text { New competences in smart } \\
\text { vertical farming especially in } \\
\text { optimising growing } \\
\text { conditions. }\end{array}$ \\
\hline $\begin{array}{c}\text { Strategic Development of } \\
\text { Scientific Research }\end{array}$ & $\begin{array}{l}\text { Novel, innovative, and } \\
\text { attractive research profile in } \\
\text { smart and sustainable } \\
\text { bioeconomy. }\end{array}$ & $\begin{array}{l}\text { New brand and } \\
\text { recognisability in smart } \\
\text { vertical farming research } \\
\text { and development. }\end{array}$ \\
\hline $\begin{array}{c}\text { Involvement of Companies } \\
\text { and Stakeholders }\end{array}$ & $\begin{array}{l}\text { Benefits and new, } \\
\text { sustainable } \\
\text { business opportunities to } \\
\text { bioeconomy companies and } \\
\text { stakeholders. }\end{array}$ & $\begin{array}{l}\text { New solutions } \\
\text { for companies' needs, e.g. in } \\
\text { sustainable food or value- } \\
\text { added products. }\end{array}$ \\
\hline
\end{tabular}




\section{How to Digitally Enhance Bioeconomy Collaboration: Multidisciplinary Research Team Ideation for Technology Innovation Essi Ryymin, Laura Lamberg \& Annukka Pakarinen}

production that fights against hunger, and for the energy-savvy, controlled cultivation of plants. One interviewee argued that smart vertical farming could give answers to famines in Africa by practical food plant development, while others also considered the importance of medical plants, organic cosmetics, and colours for sustainable businesses.

Quote 1:

"It [vertical farming] is linked to urbanisation and to the fact that there is less land available for farming and, to how we can produce food locally, close by to the end use. That's energy efficient."

Almost in all cases, the interviewees reported that they foresee new competences being developed through multidisciplinary collaboration, especially in data-driven measurement and the novel uses of smart technology in sustainable bioeconomy. Along with concrete development projects, multidisciplinary collaboration was considered to provide significant learning processes for the researchers from different domains.

The smart vertical farming project was novel to all participants. Some interviewees believed that the research team would need to establish its learning process from the very basics. They also mentioned that it is important to involve not only the researchers, but also the higher education institution students in this learning process.

Quote 2:

"Speaking of vertical farming, which is one of the subprojects [of the smart and sustainable bioeconomy development project], it is something totally new to us. We just received the container system during the summer. There's nothing there yet, we are only just starting the first farming experiments."

Quote 3:

"For instance, I was just introducing our research unit to our students on different campuses last spring, and on every campus, I asked students what we could grow in the vertical farming freight container."

All interviewees suggested that multidisciplinary collaboration in smart and sustainable bioeconomy strengthens the strategic development of scientific research and the research profile of the institution. There were also comments about increasing the amount of scientific publications, becoming an attractive research partner in smart and sustainable bioeconomy nationally and internationally, and finding new research funding sources for the current topics.

Quote 4:

"We will position ourselves in a new way, to a new position, which is, in regard of competences and research credits, higher, better. So, we will create a new kind of research profile [in smart and sustainable bioeconomy]. This will be the leading edge in our research, [for] the next three years."

Considering smart vertical farming, the interviewees wished to develop brand new data gathering methods for optimising the growing conditions of plants, and to become a recognised research partner in data-driven vertical farming. However, the research ideas related to vertical farming were in this phase still preliminary, as well as quite incoherent and fragmentary.

Some interviewees argued that it is very important to get partnered with bioeconomy companies and businesses, and to develop new solutions for their practical problems, as well as new business opportunities in regional markets. This view was echoed by other interviewees who emphasised the possibilities of vertical farming project especially to generate practical solutions for regional companies in need of plant production. One interviewee also suggested developing an application for bioeconomy companies to use.

\section{Quote 5:}

"A company receives developmental support from us [for] which the aim can be a pilot project, [or] an innovative method. It can be a prototype, a process, an operating model, it can be a service, whatever it is. This is what a company will get, and we will get a research advantage."

\section{Results of Digitally Enhanced Ideation}

The six (6) multidisciplinary researchers from the smart vertical farming project participated in a collaborative ideation workshop that aimed to help frame and prioritise their research ideas. The workshop was divided in three phases: 1) face-to-face group discussion and ideation of research interests, 2) individual implementation of a digital platform in prioritising 


\section{How to Digitally Enhance Bioeconomy Collaboration: Multidisciplinary Research Team Ideation for Technology Innovation Essi Ryymin, Laura Lamberg \& Annukka Pakarinen}

research ideas, and 3) concluding discussion of the prioritised ideas and their practical implementation. One of the six participants could unfortunately not participate in phases 2 and 3.

The digital platform used to implement the workshop was Innoduel (n.d.), which was designed to support synchronous group decision making. Innoduel was chosen because of its promising qualities in speeding up the challenging and divergent processes of collaborative decision making. A preliminary brainstorming session for the researchers had been organised earlier, before the researchers later had the opportunity to organise and rank the 20 ideas they had come up with in the prior session. Innoduel was thus used in this workshop setting to assist in continuing the earlier work, which had produced abundant ideas, but lacked prioritisation regarding which ideas ought to be moved forward.

The Innoduel platform uses an application that enables a process of collecting and voting on large or small group ideas online. The participant is invited to join a digital arena, where they can see whether a new post answers a particular question the session facilitators have created before, or can vote on existing answers. All answers will eventually end up on the arena's ranking list. However, only answers that have appeared in voting mode six times or more will be ranked. Answers that have been shown in comparison mode less than six times will be displayed below the ranking list in a random order. As a result, the participants get a prioritized list of answers (Innoduel, n.d.). The platform can be used synchronously in short-term face-to-face meetings to support shared group decision making. It can also be used individually and virtually for long-term data gathering projects, for instance, by geographically dispersed companies.

In this case study, the workshop participants were invited to an Innoduel session to answer shared questions. In this case, the questions involved the 20 research ideas brainstormed earlier, and to vote for their preferred ideas. The session was organised during the face-to-face workshop. At the beginning of the Innoduel session, the workshop participants were given an opportunity to add more research ideas, and altogether four (4) new research ideas appeared on the agenda. In the next phase, the 24 research ideas faced off against each other in randomly formed pairs in the digital arena, wherein the participants were asked to choose their preferred answer. Before voting on each answer, the participants discussed the voting criteria, framed by reference to the project's goals, and the research strategy of the higher education institution. Several qualities and values were identified as being meaningful for research ideas and decision-making in the debate, most importantly its sustainability, innovativeness (novelty), feasibility, usefulness, and scalability.

As a result of the voting, Innoduel offered a prioritised list of all the research ideas. The ranking order was based on the win rate percentage for answers in the digital arena. With Innoduel's ranking algorithm, the participants didn't have to go through every possible answer permutation to find the ranking order. Instead, the final ranking order reflected the collective opinion represented of all participants.

The five most popular research ideas that emerged from the Innoduel prioritization were, 1) Growing arctic plants in a controlled environment, including the use of new compounds, vitamins and food plants, 2) Antimicrobial ingredients in plants, 3) How cultivation conditions effect plants when optimising some properties, like plant antioxidants, 4) Organic colours, and 5) Growing functional molecules suitable for space travel.

Overall, the workshop members expressed satisfaction regarding the workshop's results. When asked for feedback immediately after using the Innoduel tool, several participants expressed satisfaction over seeing their research ideas ranked in a concrete list form. Moreover, most were happy to see what shape the "top list" had taken. Some stressed that the ranked result reflected a snapshot of the specific, quite small group gathered at that time. Two of the researchers expressed regret that research ideas with an explicit climate and sustainability focus had not made it into the top 5 . This was perhaps somewhat surprising, given the relatively more prominent focus sustainability issues had received in the researcher expectations as surveyed in the interviews. However, the researchers also voiced that the tool had pushed them towards choosing concrete and practical ideas over more abstract ones, which could explain the lower ranking of many more abstract climate-oriented proposals.

While participants viewed the digital platform as a convenient tool to help move from diverging ideation towards a convergence of sorts, some tense discourses emerged in the group concerning specifically the practical implementation and fundamental values behind the research ideas (Lamberg et al., 2020). For 


\section{How to Digitally Enhance Bioeconomy Collaboration: Multidisciplinary Research Team Ideation for Technology Innovation Essi Ryymin, Laura Lamberg \& Annukka Pakarinen}

instance, some interviewees argued that research interests should primarily support long-term sustainability goals with societal impacts, while others stressed the short-term results and need for immediate benefits for local businesses. In line with the conclusions of Schoot Uiterkamp and Vlek (2007), practicing multidisciplinarity, besides its great benefits, also appeared to be quite challenging and complicated.

The workshop participants in our research worked together on a complex object of activity, refining their joint research interests and ideas on smart vertical farming. Our qualitative analysis of the group discussion suggests that the participants, following the idea of Edwards (2010, 2012, 2017), exercised relational agency in their endeavours to expand their interpretations of research ideas. They did this by bringing to bear the various expertise and conceptual resources offered by colleagues from different disciplinary domains in the workshop. In their joint ideation, participants recognised further aspects of research as possibilities to work on. Their wider interpretations of the research possibilities drew on the strengths of collaborators from the different disciplines.

The workshop members crossed disciplinary boundaries in collaborative ideation, shared knowledge from their unique informational standpoint, and integrated knowledge by combining perspectives from various disciplines in the ranking process supported by the Innoduel platform. The intertwined processes during the workshop echoed three phases out of Fong's (2003) five processes of knowledge creation: boundarycrossing, knowledge-sharing, and knowledge integration. An interesting question for the implementation phase of the research remains: will there also be processes in new knowledge generation and collective project learning that arise for the smart vertical farming project later?

Keeping the number of workshop participants small seemed to increase opportunities for participants to contribute to discussion. It also generated more chances to tap into a broad diversity of perspectives, as Paulus, Baruah, and Kenworthy (2018) suggested. Interestingly, the method of sharing ideas in Innoduel, working individually while also synchronously on idea prioritisation, also deepened the knowledge sharing experience in face-to-face group discussions. Similar to what was highlighted by Jensen et al. (2018), combining the best of the physical and digital worlds seemed in our observations to enhance the ideation process of a multidisciplinary team, while supporting the team in framing and prioritising their research interests.

\section{Conclusions}

Contemporary challenges of ecological sustainability demand multidisciplinary collaboration. Our results indicate that multidisciplinary collaboration offers multi-voiced alternatives to research, technological development, and innovation processes, as well as opportunities for exercising relational agency. However, in practice, several challenges remain, for instance, building room for collaboration between researchers and deciding on a "shared object" (Alrøe \& Noe, 2014) or research idea.

We find it important that multidisciplinary actors be offered support in building relational agency. As relational agency develops between actors, more relevant aspects of the phenomenon under investigation can be recognised and worked on. This encourages not only the development of new technology, but broader socio-technical transitions and better management of the contextualisation and implementation of technological innovation. At its best, digital support combines group expertise and individual competence to create new viewpoints and unforeseeable solutions.

The results of this paper indicate that digital platforms may offer an impactful, process accelerating support in the kick-off phase of multidisciplinary technological innovations. The use of digital prioritization by ranking through voting may be particularly helpful when needing to shift conversations away from the abstract to a more practically oriented level. The selection process of voting forces participants to make choices between an abundance of alternatives. We thus believe that digital platforms can support ideation and the prioritisation of ideas, in a way that can be especially fruitful when paired with face to face discussion and non-digital interaction.

\section{Acknowledgments}

We would like to thank Liubov Vetoshkina for her contribution in designing the interviews and collecting interview data. 


\section{How to Digitally Enhance Bioeconomy Collaboration: Multidisciplinary Research Team Ideation for Technology Innovation Essi Ryymin, Laura Lamberg \& Annukka Pakarinen}

\section{References}

Al-Chalabi,\%M. 2015. Vertical farming: Skyscraper\%sustainability? Sustainable Cities and Society, 18: 74-75.

\%https://doi.org/10.1016/j.scs.2015.06.003\%

Alrøe, H.F., \& Noe, E. 2014. Second-order science of interdisciplinary research a polyocular framework for wicked problems. Constructivist Foundations, 10(1): 65-76.

Auerbach, C., \& Silverstein, L.B. 2003. Qualitative Data: An Introduction to Coding and Analysis. New York University Press: ProQuest Ebook Central.

Dennis, A.R., Minas, R. K., Williams, M. L. 2019. Creativity in Computer-Mediated Virtual Groups. In P.B. Paulus \& B.A. Nijstad (Eds.), The Oxford Handbook of Group Creativity: Innovation through Collaboration. Oxford University Press.

Edwards, A. 2010. Being an Expert Professional Practitioner: The Relational Turn in Expertise. Dordrecht: Springer.

Edwards, A. 2012. The role of common knowledge in achieving collaboration across practices. Learning, Culture and Social Interaction, 1(1): 22-32.

Edwards, A. 2017. Relational Expertise: A CulturalHistorical Approach to Teacher Education. In Peters, M.A., Cowie, B. \& Menter, I. (Eds)., A Companion to Research in Teacher Education, Singapore: Springer: 555-567.

Fong, P.S.W. 2003. Knowledge creation in multidisciplinary project teams: an empirical study of the processes and their dynamic interrelationships. International Journal of Project Management, 21: 479486.

Geels, F.W. 2011. The multi-level perspective on sustainability transitions: Responses to seven criticisms. Environmental Innovation and Societal Transitions, 1(1): 24-40.

DOI: $10.1016 /$ j.eist.2011.02.002

Geels, F.W. 2019. Socio-technical transitions to sustainability: a review of criticisms and elaborations of the Multi-Level Perspective. Current Opinion in Environmental Sustainability, 39: 187-01.

DOI: 10.1016/j.cosust.2019.06.009

Innoduel (n.d.). Employee engagement and decision making made easy. Retrieved September 8, 2020 from https://www.innoduel.com/en/product

Jensen, M.M., Thiel, S., Hoggan, E. \& Bødker, S. 2018. Physical Versus Digital Sticky Notes in Collaborative Ideation. Computer Supported Cooperative Work, 27: 609-645.

Kerr, D.S., \& Murthy, U.S. 2009. Beyond brainstorming: The effectiveness of computer-mediated communication for convergence and negotiation tasks. International Journal of Accounting Information Systems, 10(4): 245-262.
Korde, R. \& Paulus, P.B. 2017. Alternating individual and group idea generation: Finding the elusive synergy. Journal of Experimental Social Psychology, 70: 177190.

Kuhn, T.S. 1962. The Structure of Scientific Revolutions. Chicago: University of Chicago Press.

Lang, D.J., Wiek, A., Bergmann, M., Stauffacher, M., Martens, P., Moll, P., Swilling, M. \& Thomas, C.J. 2012. Transdisciplinary research in sustainability science: practice, principles, and challenges. Sustainability Science: 7, 25-43.

Lamberg, L., Ryymin, E., Paavola, S., Vetoshkina, L. 2020. Value Discussions in Interdisciplinary Research: Facilitating Problem Definitions in Bioeconomy. Manuscript in preparation.

Norris, P.E., O'Rourke, M., Mayer, S.A. \& Halvorsen, K.E. 2016. Managing the wicked problem of transdisciplinary team formation in socio-ecological systems. Landscape and Urban Planning, 154: 115122.

Paulus, P.B., Baruah, J. \& Kenworthy, J.B. 2018. Enhancing Collaborative Ideation in Organizations. Frontiers in Psychology, 9: 2024.

Pohl, C. and Hirsch Hadorn, G. 2007. Principles for Designing Transdisciplinary Research. München: oekom verlag.

Pohl, C. \& Hirsch Hadorn, G. 2008. Methodological challenges of transdisciplinary research. Natures Sciences Sociétés, 16(2): 111121.

Ramadier, T. 2004. Transdisciplinarity and its challenges: The case of urban studies. Futures, 36(4): 423-439.

Schoot Uiterkamp, A.J.M., \& Vlek, C.A.J. 2007. Practice and outcomes of multidisciplinary research for environmental sustainability. Journal of Social Issues, 63(1): 175-197.

Vick, T.E., Nagano, M.S. \& Popadiuk, S. 2015. Information culture and its influences in knowledge creation: Evidence from university teams engaged in collaborative innovation projects. International Journal of Information Management, 35: 292-298.

Yagolkovskiy, S.R. 2015. Creativity in Face-to-Face and Computer-Mediated Brainstorming. Psychology. Journal of the Higher School of Economics, 12 (4): 184191. 


\section{How to Digitally Enhance Bioeconomy Collaboration: Multidisciplinary Research Team Ideation for Technology Innovation Essi Ryymin, Laura Lamberg \& Annukka Pakarinen}

\begin{abstract}
About the Authors
Dr. Essi Ryymin holds a PhD in Educational Sciences from the University of Tampere (TUNI, 2008). She had held several educational specialist, project manager and R\&D manager positions in the public and private sector in competence development and the digitalization of education. She currently acts as Principal Research Scientist in Häme University of Applied Sciences and leads the Future Work Research \& Development Team with a focus and interest on exploring transforming work, future skills of professionals, and continuous learning. Her works have been published in international journals such as E-learning and Education, Computer \& Education, and International Journal for Cross-Disciplinary Subjects in Education.
\end{abstract}

Laura Lamberg holds a master's degree in Political Science from the University of Helsinki (2018). Lamberg works as a project researcher at the HAMK Edu research unit at Häme University of Applied Sciences. Her current research interests cover a scope of the social studies of science and technology, interdisciplinary collaboration, sustainability transitions, and social complexity. Lamberg began $\mathrm{PhD}$ studies at the University of Helsinki in 2020. Her academic accomplishments have been recognized by the Academy of Finland (1st place in Viksu Science competition in 2012), and the University of Helsinki (best master's thesis award for Political Science in 2018).

Dr. Annukka Pakarinen holds a $\mathrm{PhD}$ in Environmental Solutions in Agriculture and a master's degree in Chemical Engineering. She has expertise in utilizing and treating (physical, chemical, enzymatic, etc.) plant and waste based raw materials in biofuel production. Currently she works as the Director of HAMK Bio research unit, closely following the field of Bioeconomy from primary production to value added refining and smart solutions. She has also been the founder of a start-up company in the field of circular economy.

Citation: Ryymin, E., Lamberg, L., \& Pakarinen, A. 2020. How to Digitally

Enhance Bioeconomy Collaboration: Multidisciplinary Research Team

Ideation for Technology Innovation. Technology Innovation Management

Review, 10(11): 31-39.

http://doi.org/10.22215/timreview/1401

(cc) BY 